\title{
Autosomal recessive spastic ataxia-optic atrophy-dysarthria syndrome
}

INSERM

\section{Source}

INSERM. (1999). Orphanet: an online rare disease and orphan drug data base. Autosomal recessive spastic ataxia-optic atrophy-dysarthria syndrome. ORPHA:254343

A rare, genetic, autosomal recessive spastic ataxia disease characterized by onset in early childhood of spastic paraparesis, cerebellar ataxia, dysarthria and optic atrophy. 